\title{
Mesoporous materials for encapsulating enzymes
}

\section{Chia-Hung Lee ${ }^{a}$, Tien-Sung Lin ${ }^{b}$, Chung-Yuan Mou ${ }^{a, *}$}

\author{
a Department of Chemistry, National Taiwan University, Taipei 106, Taiwan \\ b Department of Chemistry, Washington University, St. Louis, MO 63130, USA
}

Received 9 October 2008; received in revised form 8 January 2009; accepted 2 February 2009

Available online 23 February 2009

\section{KEYWORDS \\ Biocatalysis; \\ Enzymes; \\ Immobilization; \\ Mesoporous \\ materials; \\ Nanospace}

\begin{abstract}
Summary The unique properties of mesoporous silica (MPS) materials were utilized to immobilze enzymes: huge surface area, modifiable surface, and restricted pore nanospaces. The enzyme confinements in the nanochannels of MPS materials generate synergistic effects that enhance enzyme stability, improve product selectivity, and facilitate separation and reuse of enzymes. The physical chemistry of enzyme confinement, methods of immobilization, catalytic activity and advantages of protein confinements are discussed. In the end, we show that immobilized enzymes in the nanospaces of MPS can be applied as viable biocatalysts for chemical and pharmaceutical industries.

(c) 2009 Elsevier Ltd. All rights reserved.
\end{abstract}

\section{Introduction}

The utilization of enzymes as biocatalysts has become an important avenue in chemical and pharmaceutical industries to prepare biochemical products, biosensors and drugs [1-5]. Enzymatic reactions are environmentally and user

Abbreviations: CLEAs, cross-linked enzyme aggregates; COs, catechol oxidases; COD, cholesterol oxidase; CPO, chloroperoxidase; CT, $\alpha$-chymotrypsin; cyt c, cytochrome c; DTBC, 3,5-di-tertbutylcatechol; DTBQ, 3,5-di-tert-butylquinone; GA, glutaraldehyde; $\mathrm{Gdn}-\mathrm{HCl}$, guanidine- $\mathrm{HCl}$; $\mathrm{Gl}$, glucose isomerase; $\mathrm{GOx}$, glucose oxidase; GPTMS, c-glycidoxypropyltrimethoxylsilane; $\mathrm{Hb}$, hemoblogin; HRP, horseradish peroxidase; MP-11, microperoxidase11; MPS, mesoporous silica; NTA, nitrilotriacetic acid; PGA, penicillin $\mathrm{G}$ acylase; PMO, periodic mesoporous organosilane; SENs, single enzyme nanoparticles; SOD, superoxide dismutase.

* Corresponding author. Tel.: +886 233665251 ; fax: +886223660954.

E-mail address: cymou@ntu.edu.tw (C.-Y. Mou). friendly. The catalytic efficiency is high under normal mild reaction conditions. Enzymes provide stereo-(enantio-) and regio-selectivity. High regioselectivity can simplify the multi-step processes to a single step especially for the protection and deprotection in the traditional organic synthesis. For example, aspartame ( $\alpha$-L-Asp-L-Phe-OMe), was prepared by enzymatic reaction in a single step without protection-deprotection steps [6]. The stereoselectivity can produce chiral compounds which is important in asymmetric synthesis of optically active compounds. For example, lipases have been widely applied in the kinetic resolution of a racemic compound to achieve high optical purity [7].

However, most of native enzymes exhibit high reactivity and selectivity only under normal conditions. Under extreme temperatures or $\mathrm{pH}$, enzymes are easily inactivated due to denaturation, either by changes of conformation or other transformations of stereo chemical structure. Thus, native enzymes often suffer severe limitations in broader applications. Moreover, the utilization of natural enzymes has other processing difficulties such as the reuse of 
enzymes, product contamination and separation. One of the approaches to resolve these difficulties is to immobilize enzymes on solid surfaces which can produce recoverable and stable heterogeneous biocatalysts.

There is a long history for enzyme immobilization on solid supports [8], particularly on silica gel [9]. However, due to small pore size and non-open pore hindrance, the immobilized enzymes usually show lower activity than the free enzymes. Furthermore, the non-uniform pore sizes of most silica gel supports made processes less reproducible.

Unlike sol-gel silica, mesoporous silica (MPS) materials provide tunable and uniform pore system, functionalizable surfaces, and restricted nanospaces for enzyme immobilization. MPSs have generated vast interest ever since they were synthesized and characterized by Mobil researchers in 1992 $[10,11]$. Recently, many research groups have immobilized enzymes on MPS which showed improvement on enzyme stability, catalytic activity, products specificity, and resistance to extreme environmental conditions [12-24]. In addition, confined enzymes in the nanospaces of MPS provide a good model to understand the enzyme action inside the cell. This concept arises from that the highly crowded environment enzyme molecules are primarily located inside the organelles. Thus, most enzymes in vivo perform under a crowded environment where unfolding and aggregations are prevented. Due to the larger and controllable pore sizes of MPS, one may even encapsulate two or more different enzymes to perform parallel or sequential catalytic reactions. In addition to immobilize enzymes, controlled release of biomolecules from MPS supports provides a better protection by preventing biopharmaceuticals from degradation and decrease of non-specific release. MPS materials show biocompatibility, low cytotoxicity, large surface areas, and easy functionalization which are suitable as vehicles for genes, enzymes and drugs delivery [25,26]. Recently, biomimetic model compounds (artificial enzymes) have been encapsulated in MPS to improve the catalytic activity [27-29]. It was recognized that the rigid structure and pore surface of functionalized MPS can mimic protein skeleton where the active sites are held stably with a fixed configuration to carry out the presumed enzymatic functions with good turnover efficiency.

There have been three previous reviews on similar subject matter, Hartmann reviewed ordered mesoporous materials for bioadsorption and biocatalysis [12], Yiu et al. considered enzyme immobilized on mesoporous solids as a special case of an inorganic-organic hybride [13], and Zhao et al. addressed immobilizing catalysts on porous materials [14]. In this review, we focus our attention to the physical principles of enzyme immobilization in the nanospaces of MPS materials. We discuss the nature of nanostructure, pore size, surface charges, the functionalization, and the methods of immobilization, such as physical adsorption, electrostatic interaction, covalent binding, metal affinity

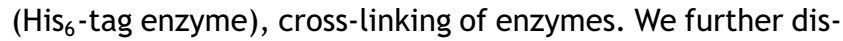
cuss catalytic properties of immobilized enzymes, turnover efficiency, and products selectivity. In the end, we discuss a novel application of MPS for artificial enzymes to explore the potential applications of immobilized enzymes in confined nanospaces of MPS in biocatalysis. We report what have been developed and achieved in the most recent studies up to mid 2008 with respect to the syntheses and characterizations of active MPS nanostructures for enzyme immobilization.

\section{Physical chemistry of protein confinement}

We first review the physical chemistry of proteins confined in nanospace. Before the advent of MPS, studies on protein confinement were generally done on silica hydrogels by encapsulation in a sol-gel synthesis process. In 2001, Eggers and Valentine carried out a circular dichroism study with sol-gel encapsulated proteins to examine the effects of macromolecular crowding and hydration effects on protein stability [30]. Their analyses identified two main factors which can affect the stability of protein in confined environments: excluded volume effects and water structure changes in confined space. A model calculation by Zhou and Dill showed that proteins inside a confined space can be stabilized by folding forces which are different from those for proteins in solution [31]. In particular, some expanded configurations of the unfolded chain will not be allowed inside the confined space, due to excluded volume effect. Small cages are predicted to increase the stability of the native state by as much as $15 \mathrm{kcal} / \mathrm{mol}$. A Monte Carlo simulation and experimental measurements of activity and stability further confirmed the confinement can enhance protein stability [32]. Recently, Sorin and Pande [33] showed in a molecular dynamics simulation that carbon nanotube confinement denatures protein helices. There, the physical confinement of solvated biopolymers decreases solvent entropy, which in turn leads to a reduction in the organized structural content of the polymer. Physically, confinement alters both the polymer configurations of the helix and the nature of water. They reported helix formation of an alanine peptide is disfavored inside a nanotube relative to that in bulk solution. The decreased helical propensity of the peptide with decreasing vessel size, and thus decreasing solvent entropy, is a general hydrophilic destabilization phenomenon. Most recently, Schirò et al. studied the effect of hydration on the dynamics of protein in confined geometry using elastic neutron scattering of met-myoglobin encapsulated on sol-gel [34]. They showed that the level of hydration in the porous silica matrix does affect strongly the mean square displacements of protons of the confined protein, but not in the bulk protein. They further showed that the effect of confinement depends markedly on hydration and has a maximum at about 35\% water/protein fraction corresponding to full first shell hydration. These studies showed theoretically and experimentally that confinement of protein in nanospace does not necessarily stabilize its structure. There are two factors to consider: (a) the excluded volume effect which stabilizes the folded state and (b) change of hydration which may either stabilize or de-stabilize the native state depending on the perturbation of the hydration shell. In the field of enzyme immobilization in porous materials, most researchers however ignored the hydration effect and only focused on the effect of limited configuration available to protein structure.

In a recent study of protein encapsulation in mesoporous silicate by Winter's group is illuminating in that they identified both hydration and excluded volume as factors determining the stability of the confined protein [35]. 
Table 1 A summary of characteristic properties of various mesoporous silica materials employed for encapsulating enzymes.

\begin{tabular}{|c|c|c|c|c|c|}
\hline Mesoporous materials & Silica source & Template & Description & $\begin{array}{l}\text { Pore diameter } \\
(\mathrm{nm})\end{array}$ & Refs. \\
\hline MCM-41 & $\begin{array}{l}\text { TEOS, sodium } \\
\text { silicate }\end{array}$ & $\mathrm{C}_{n} \mathrm{TMA}^{+}(n=12-18)$ & 2D hex. channels & $2-10$ & {$[11]$} \\
\hline MCM-48 & $\begin{array}{l}\text { TEOS, sodium } \\
\text { silicate }\end{array}$ & $\begin{array}{l}\mathrm{CTAB}, \\
\mathrm{C}_{16} \mathrm{H}_{33}\left(\mathrm{CH}_{3}\right)_{2} \mathrm{~N}\left(\mathrm{CH}_{2}\right)\left(\mathrm{C}_{6} \mathrm{H}_{5}\right) \text {, } \\
\text { Gemini } \mathrm{C}_{m-12-m}\end{array}$ & Bicontinuous & $2-4$ & [111] \\
\hline FSM-16 & $\begin{array}{l}\text { Polysilicate } \\
\text { kanemite }\end{array}$ & $\mathrm{C}_{n} \mathrm{TMA}^{+}(n=12-18)$ & 2D hex. channels & $\sim 4$ & [112] \\
\hline SBA-1 & TEOS & $\begin{array}{l}\mathrm{C}_{n} \mathrm{H}_{2 n+1} \mathrm{~N}\left(\mathrm{C}_{2} \mathrm{H}_{5}\right)_{3} \mathrm{X} \\
(n=12-18), 18 \mathrm{~B}_{4-3-1}, \\
\mathrm{C}_{n-s-1}(n=12-18)\end{array}$ & $3 \mathrm{D}$ cubic mesostructure & $2-3$ & [113] \\
\hline SBA-15 & $\begin{array}{l}\text { TEOS, sodium } \\
\text { silicate }\end{array}$ & $\begin{array}{l}P_{123}, P_{85}, P_{65}, B 50-1500 \\
\left(B_{10} E_{16}\right), \text { Brij } \\
97\left(C_{18} H_{35} E_{10}\right)\end{array}$ & 2D hex. channels & $5-30$ & [114] \\
\hline SBA-16 & TEOS, TMOS & $\mathrm{F} 127, \mathrm{~F} 108$, or F98 & Spherical cages & $5-30$ & {$[115]$} \\
\hline MCF & TEOS & $\begin{array}{l}\text { F127 }\left(\mathrm{EO}_{106} \mathrm{PO}_{70} \mathrm{EO}_{106}\right) \\
\text { with } \mathrm{TMB}\end{array}$ & Cellular foam & $10-50$ & [116] \\
\hline HMS & TEOS & $\mathrm{C}_{m} \mathrm{H}_{2 m+1} \mathrm{NH}_{2}(m=8-22)$ & Disordered mesostructure & $2-10$ & [117] \\
\hline MSU-X & TEOS, TMOS & $\begin{array}{l}\mathrm{C}_{m} \mathrm{EO}_{n}(m=11-15), \\
\mathrm{C}_{8} \mathrm{PhEO}_{n}, \mathrm{EO}_{13} \mathrm{PO}_{30} \mathrm{EO}_{13}\end{array}$ & Disordered mesostructure & $2-15$ & [118] \\
\hline $\mathrm{IBN}-\mathrm{X}$ & TEOS & $\begin{array}{l}\mathrm{F} 108, \mathrm{~F} 127, \mathrm{P} 65, \mathrm{P} 123 \\
\text { with } \mathrm{FC}-4 \text { and } \mathrm{TMB}\end{array}$ & Nanoparticle & $5-20$ & [119] \\
\hline PMOs & $(\mathrm{RO})_{3} \mathrm{Si}-\mathrm{R}^{\prime}-\mathrm{Si}(\mathrm{OR})_{3}$ & $\begin{array}{l}\text { CTAB, OTAB, CPB, P123, } \\
\text { F127, Brij 56, Brij } 76\end{array}$ & $2 \mathrm{D}$ or $3 \mathrm{D}$ hex. & $2-20$ & {$[120]$} \\
\hline
\end{tabular}

They found RNase A confined in MCM-48 is stabilized by $30^{\circ} \mathrm{C}$ in increased unfolding temperature. The increased stability is due to both restrictions in conformational space and increased strength of hydration in the narrow silica pore. The later effect is expected to depend on the surface chemistry of MPS. When the internal surface of MPS is hydrophobized by functionalization, Reis et al. found a higher rate of esterification catalyzed by an embedded lipase [36]. This is interpreted as less perturbation of the hydration water and provides better retention of the enzyme structure.

\section{Mesoporous materials}

The MPS materials come in different pore size and shape. The pores of these materials can be further tailor-made, and the surface be functionalized. It is critical to select a proper pore size, surface properties (charges, hydrophilicity/hydrphobicity), and spatial structures of MPS to carry out effective immobilization of the targeted enzymes which have different molecular size, shape and side-chain functional groups which yield electrostatic charges. Furthermore, MPS with rigid and open large pore structures and controllable pore sizes can facilitate mass transport of enzyme substrates and the products, and allow enzymes to be spontaneously entrapped inside the mesopores under neutral mild conditions. Table 1 summarizes the characteristic properties of various MPS materials employed for encapsulating enzymes. A summary of published research in enzymes immobilized on MPS materials up to 2005 was given in Ref. [12].

\section{Functionalization}

MPS possesses well-defined structure and high density of surface silanol groups which can be modified with a wide range of organic functional groups for immobilizing biomolecules [22]. The surface functional groups play several roles in enzyme immobilization: (i) to change the surface charge of MPS for controlling electrostatic interaction with adsorbed enzyme, (ii) to chemically link with the amino acid groups of the targeted enzyme, and (iii) to decrease the size of pore entrance for entraping the enzymes in the nanochannels [22]. Fig. 1 illustrates a few routes for surface functionalization of MPS, with examples for the above three roles. Below we briefly summarize the preparation methods of the incorporation of organosilanes into MPS:

\section{Grafting (post-synthesis modification)}

The first step, the surfactant molecules in as-synthesized samples are removed by solvent extraction or calcinations. Although the calcinations can completely remove the surfactant template, this would lead to a decrease in the density of silanol groups for the subsequent modification. In addition to calcinations, ethanolic extraction under acidic condition can remove ionic template effectively [37]. Oxidative digestion of surfactants is another method, Zhao et al. used $\mathrm{HNO}_{3}-\mathrm{H}_{2} \mathrm{O}_{2}$ system to completely remove pluronic P123 from SBA-15 with high density of silanol groups left [38].

After the removal of templates, organosilanes can be grafted onto the surface of silanol-containing MPS by using trichloro- or trialkoxy-organosilanes under the reflux. A 
<smiles></smiles>

(b')<smiles>[Si]O[Si](CCCS)(O[SiH3])OCl</smiles>

(a)<smiles>O=S(=O)(O)CC[Si](O[Si])(OCl)O[Si]O</smiles>

(a')

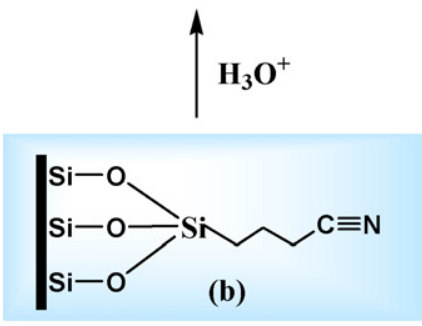<smiles>CO[SiH2]CCCS</smiles>

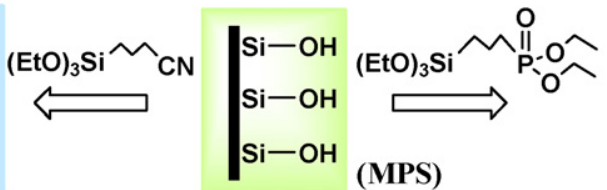<smiles></smiles><smiles>CO[SiH2]CCCC1CO1</smiles>

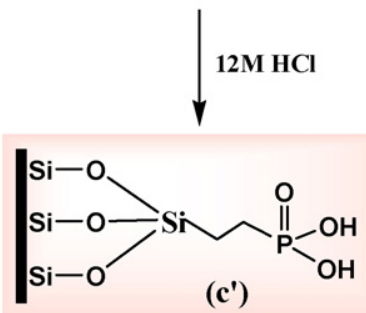

Figure 1 Surface modification of MPS with different functional groups: (1) MPS with sulfonic acid groups from the post-oxidation of mercapto group $\left(a, a^{\prime}\right)$, (2) carboxylic groups from the hydrolysis of cyano groups (b, b'), (3) phosphoric acid groups from the hydrolysis of the diethylestersilanes $\left(c, c^{\prime}\right)$, and (4) epoxide groups react with the amine groups of enzyme molecules via ring opening reaction $\left(d, d^{\prime}\right)$.

series of organosilanes including amine, thiol, chloride, cyano, ester, epoxy, aldehyde, anhydride, isocyanato, phospho, imidazole, ammonium, acryl, alkyl, and phenyl are all commercially available for grafting [39]. The incorporation of a reactive group on the surface can provide the opportunity for post-modification of the initial organic moiety to other functional groups. For example, aldehyde-modified
MPS can be obtained by the reaction of amine modified MPS with glutardialdehyde (Fig. 2 step b) [40]. Thus, different characters of functional groups can generate different interactions to the host molecules such as hydrogen bonding, electrostatic attraction, or covalent binding. Carboxylate functional group is often useful to link positively charged enzymes (see below). An organoalkoxysilane with cyano

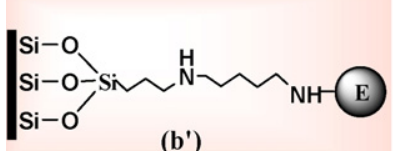

(b')

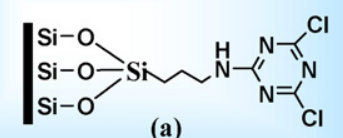

(a)

(2) $\mathrm{NaCNBH}_{3}$<smiles>O=CCCC=NCCC[Si](O[Si])(O[Si])O[Si]</smiles>

(b)

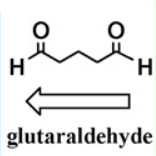

glutaraldehyde

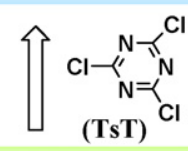
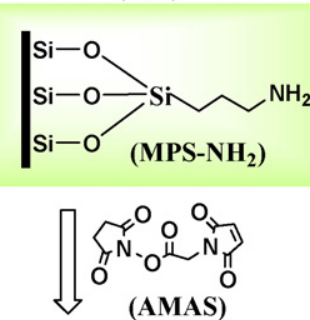

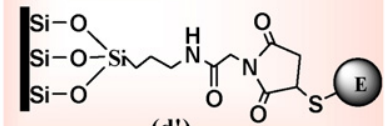

(d')

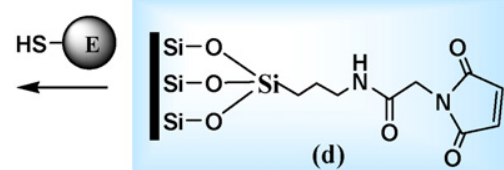

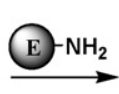

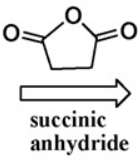<smiles>O=C(O)CCC(=O)NCCC[Si](O[Si])(O[Si])O[Si](O)(Cl)O[Si]</smiles>

(c) (a')

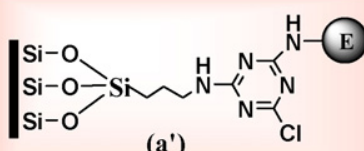


group was first modified in the surface of MPS, the modified groups were following hydrolysis to the acid groups in the presence of sulfuric acid as a catalyst (Fig. 1 step b and $b^{\prime}$ ) [39]. Another approach is the hydrolysis of ester bonds in the estersilanes into the corresponding acid groups (Fig. 1 step $c$ and $c^{\prime}$ ) [41].

\section{Co-condensation (direct synthesis)}

In this one-pot process, organosilanes are added directly in the synthesizing gel solution together with silica source [42]. A portion of silica precursor for the sol-gel mixture was replaced by different ratio of organosilanes. Then, the surfactant molecules are removed by extraction under an acidic [43], salt [44], or organic solvent [45]. The advantages of cocondensation are high loading density of the organosilanes [46] and the homogeneous distribution of the functional groups which can be achieved without a large decrease in surface area, pore size, and pore volume. However, one problem with this method is the extraction efficiency for the block copolymer systems which were only ca. 80\%. Another concern of this approach is that the functional groups may be destroyed under the severe conditions of sol-gel reaction and surfactant extraction. The incorporation of a reactive vinyl group into MPS provided the possibility of creating a wide variety of functional groups by post-modification of the initial functional groups.

\section{Surfactant displacement}

Here the direct surface silylation and simultaneous surfactant removal of MPS is carried out in a single step without prior calcinations. This process produces a uniform monolayer coverage with higher amounts of functionalized organosilanes on the surface. Antochshuk and Jaroniec studied the modification of MCM-41 and Ce-MCM-41 by using organosilanes as solvents and modifying agents in a single step [47]. Liu et al. achieved simultaneous extraction of surfactant and grafting of organosilanes by using alcohol as the solvent [48]. This method gives a better control of the monolayer coverage of the surface.

\section{Immobilization methods}

It is critical in the preparation protocols for the immobilization of enzymes in confined nanospaces to retain the integrity of tertiary structure and leave the active sites accessible. By immobilizing enzymes, the enzymatic reaction may be carried out under a non-aqueous media for large-scale applications. The solid supports make the enzyme molecules more robust so the catalysts can be reused for several times after easy separation from the reaction media. The above situations demand proper immobilization methods tailored for particular needs.

\section{Physical adsorption}

This is one of the simplest approaches to immobilize enzyme and it is usually not directly affect the active sites. Although involving only weak interactions such as hydrogen bonding, hydrophobic and van der Waals attraction, the immobilization of large proteins would be favorably using this approach because of many additive interactions. Thus, immobiliza- tion of complex proteins of multiple units would be possible without the disruption of subunits. However, this kind of interactions is usually too weak to prevent the enzyme molecules from leaching into the reaction media.

Diaz and Balkus immobilized cytochrome (cyt c), papain, trypsin onto MPS and a layered niobium oxide [22]. Deere et al. studied the relations of pore size and surface charge in the oxidative activity of immobilized cyt c [23]. Urabe et al. immobilized hemoglobin on FSM-16 material which retains its activity under high salt and guanidine- $\mathrm{HCl}(\mathrm{Gdn}-\mathrm{HCl})$ concentration [49]. Stevens and coworkers studied the separation of biological molecules by physical adsorption in MPS of different pore size. They showed that the adsorbent rate depended on the size of the adsorbing molecule and the pore size of MPS. Thus, riboflavin with the smallest molecule size showed the fastest rate of adsorption [50]. Blanco et al. demonstrated that octyl-modified MPS for immobilized lipase can generate strong hydrophobic interactions [51].

\section{Ionic (electrostatic) attraction}

This is an easy method of immobilization by invoking the zeta potential of silica and the opposite charges of enzymes. Charges of pore wall and enzyme can be varied to provide optimum condition for immobilization. To provide negative charges on MPS, one can incorporate aluminum atoms into the silica framework ( $\mathrm{Si}$ sites replaced by Al atoms, Al-MPS) to enhance the binding of positively charged enzymes. Lee et al. showed that Al-MPS materials improve the binding affinity with cyt $c$, and increase the loading capacity on the nanopore surfaces $[16,17]$. One can also modify MPS surface with amine groups to bind negatively charged enzymes, and with carboxylate groups to encapsulate positively charged enzymes as demonstrated previously in the immobilization of glucose oxidase (GOx, negatively charged) and organophosphorus hydrolase (positively charged enzyme) in the nanochannels of functionalized SBA-15 [18,52].

Since the electrostatic interactions could be screened by the ions in solution, loadings by charge interaction would be affected by the ionic strength of solution. Deere et al. showed adsorption of cyt $c$ in MPS decreased drastically with increasing ionic strength of the solution [23]. Hudson et al. also showed that adsorption of cyt $c$ and xylanase onto SBA15 and MSE materials was inhibited by increasing the ionic strength of the initial protein solutions [53].

Another approach to generate electrostatic attraction is to adjust the $\mathrm{pH}$ of the solution [23,54,55]. Proteins can exist as neutral, positively or negatively charged state. The charged state of a protein is determined by the isoelectric point $(\mathrm{pl})$. At a $\mathrm{pH}$ below their $\mathrm{pl}$, proteins carry net positive charge; and above their pl, they carry net negative charge. Thus, the attraction and repulsion of the enzyme molecules and MPS surface can be regulated by the change of $\mathrm{pH}$ value. When the $\mathrm{pH}$ is below the pl, the electrostatic attractions between the positive charges of enzyme molecules and negative charge of MPS surface induce more loadings. Vinu et al. showed that cyt $c$ adsorbed on different MPS supports was greatly influenced by the $\mathrm{pH}$ of the solution [56]. Similar pH effect was also reported by Takahashi et al. on the immobilization of horseradish peroxidase (HRP) and subtilisin on FSM-16, MCM-41, and SBA-15 [57]. Recently, Hudson et al. reported the adsorption of cyt $c$ and xylanase 
on SBA-15 and organo-functionalized SBA-15 carriers. They showed that the electrostatic forces dominate the interaction between enzymes and SBA-15, while weak hydrophobic forces provide the major interaction between proteins and organofunctionalized SBA-15 [53].

\section{Covalent binding}

In general, covalent binding consists of the modification of surface silanol groups with nucleophilic (amine, thiol) or electrophilic groups (active carboxylic acid, alkyl chloride). The amine groups of an enzyme molecule contain the $\mathrm{N}$-terminal $\alpha$-amine of the protein chain and the aminecontaining side chain groups include lysine, arginine, and histidine. Alkylation and acylation can be carried out with the amine groups of enzyme molecules. For alkylation, MPS surface can be modified with active alkyl groups, e.g., alkyl halides so it can react with an amine nucleophile of the enzyme molecules (Fig. 2 step a and $a^{\prime}$ ). For acylation, the surface of MPS can be modified to active carbonyl groups so it undergoes a substitution reaction with the amine groups (Fig. 2 step $c$ and $c^{\prime}$ ). Another approach is to graft epoxy groups on the surface of mesopores and react with amino groups $\left(-\mathrm{NH}_{2}\right)$ of the enzyme (Fig. 1 step $\left.d^{\prime}\right)$. Epoxy groups functionalized MPS can be obtained by attaching c-glycidoxypropyl-trimethoxylsilane (GPTMS) containing epoxy groups (Fig. 1 step d) [58]. Cysteine residue is the only source of sulfhydryl group in enzyme molecules. The immobilization of cysteine-containing enzyme on MPS is achieved by the reaction of the enzyme with mercapto or maleimide modified MPS to produce a disulfide bond or a Micheal-type addition reaction (Fig. 2 step $d^{\prime}$ ). We may also immobilize cysteine-containing enzymes on MPS by alkylation to form a stable thioether bond or acylation to form a relatively unstable thioesters.

Fig. 2 shows a few possible routes for enzymes immobilization on MPS surface via the covalently binding technique. Other bioconjugate techniques can further extend the covalent approach to greater possibility [59]. For instance, the surface modified with glutaraldehyde or glutardialdehyde can provide a versatile linker to joint the polypeptides of enzymes to the nanopore surface (Fig. 2 step b and b') [60]. However, if the reaction conditions under the immobilization process modify the electronic structure of the enzyme or change the tertiary structure of the protein, then the outcome of the catalytic reaction will be affected. This is evidenced from our previous studies of cyt $c$ immobilized on the mercapto modified MPS where the thio-group binds strongly with the iron center (active site) of the heme group of cyt $c$ and changes the catalytic activity [17].

The covalent binding technique generally gives better stability against leaching. Thus it can be used for long period of withstanding repeated filtering/washing process [61]. However, fixed enzymes on the solid surface may severely alter the enzyme conformation and decrease the enzyme activity. Recently, Lü et al. functionalized the cubic MPS with glycidoxypropyl groups for covalent immobilization of Penicillin G acylase (PGA) [58]. PGA can catalyze the hydrolysis of penicillin $\mathrm{G}$ to 6-aminopenicillanic acid and phenylacetic acid. The initial specific activity of the immobilized enzyme via covalent binding was higher than that of the physical adsorption. After re-use for 10 times, the immobilized enzymes via covalent binding showed $72 \%$ retention of its initial activity. Li et al. reported the immobilization of triacylglycerol lipase (from porcine pancreas) on aldehyde modified MPS by covalent binding. They also showed that the immobilized enzyme exhibited a high thermal stability, reusability and $76 \%$ of high activity [62].

Most recently, Schlossbauer et al. developed the surface-based chemistry with azide-alkyne click reaction to covalently immobilize enzyme to the surface of mesopores. This method gives very high surface loading of enzyme without pore-blocking [63] (see Fig. 3).

\section{Metal affinity ( His $_{6}$-tag enzyme)}

Immobilizing $\mathrm{His}_{6}$-tag enzymes by metal affinity have the advantages of high stability, highly enzymatic activity, and reusable solid supports. Since the six histidine groups are usually expressed on the $\mathrm{N}$ - or C-terminal of enzyme molecules, the active center of the immobilized enzyme is less affected. Thus, this approach can avoid the unfolding of enzyme molecules during the immobilization process. Since the multi-dentate of the six histidine groups is coordinated to a single metal ion, a strong coordinate covalent binding could be generated to stabilize enzyme molecules (see Fig. 4). Another advantage comes from the immobilized enzyme can be displaced from the solid supports by the addition of competitive ligands such as histidine or imidazole. Thus, good activity can be maintained while at the
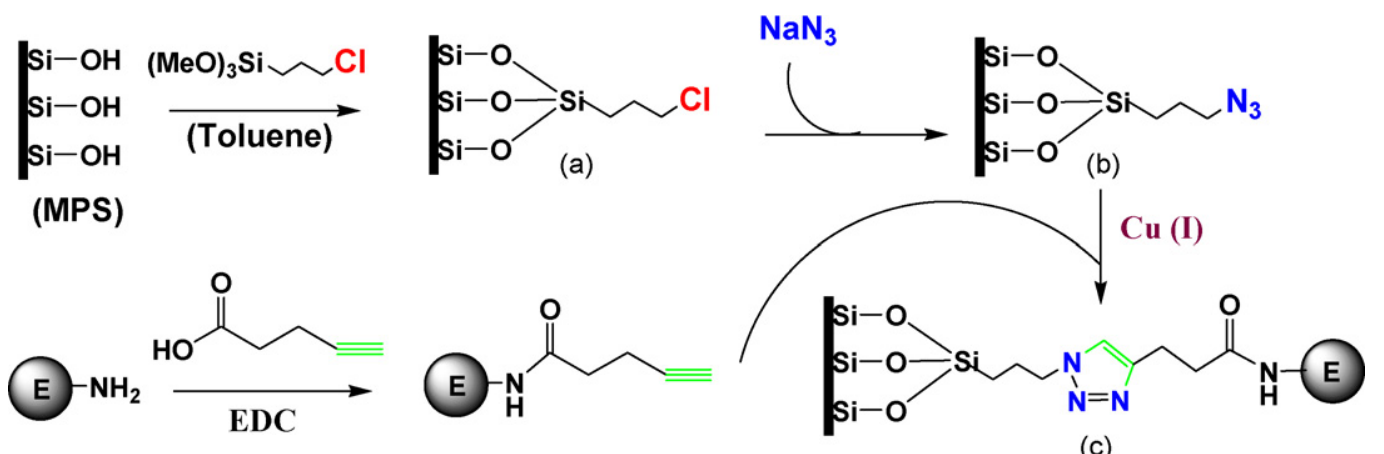

Figure 3 Click chemistry to covalently attach enzymes on MPS: (a) surface modified with 3-chloropropyltrimethoxysilane, (b) post-substitution by sodium azide, and (c) copper(I)-catalyzed azide-alkyne cycloaddition (click reaction). 

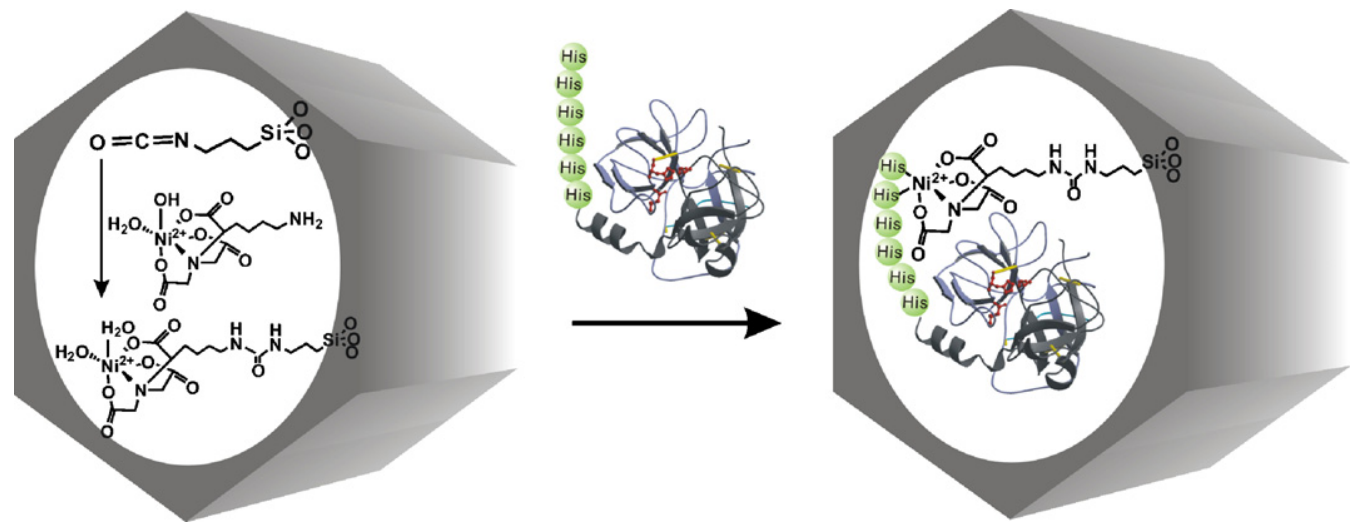

Figure 4 Surface modification of MPS with Ni(II) complexes to immobilize His 6 -tagged enzymes.

same time re-use of solid supports can be achieved. Miyazaki and Maeda modified the silica micro-channel surface with nickel complexes to immobilize $\mathrm{His}_{6}$-tag enzymes through coordinate binding [64]. Immobilizing enzymes by metal affinity are also applied in other nanoparticle systems. Xu et al. synthesized FePt magnetic nanoparticles with nickel terminated nitrilotriacetic acid (NTA) [65]. They showed these nanoparticles have high affinity and specificity toward histidine-tagged proteins. Taton and coworkers reported the bioconjugation of histidine-tagged enzymes to $\mathrm{Cu}^{2+}$ iminodiacetic acid modified magnetomicelle surface. They also demonstrated the advantages of using this approach in protein bioseparation and enzyme recycling [66]. Recently, we applied the metal affinity technique to immobilize a truncated single subunit of superoxide dismutase (CuZnSOD) on SBA-15. Native CuZnSOD enzymes contain two subunits with a molecular weight of approximately $40 \mathrm{kDa}$.

\section{Cross-linking}

This is a simple and effective method to immobilize enzymes on MPS surfaces with high stability because it can prevent enzymes from leaching and consequently improve the enzymatic stability. Cross-linking is usually involved a twostep process. First, enzyme molecules are adsorbed inside the nanochannels of MPS. Second, the adsorbed enzymes are cross-linked by adding glutaraldehyde to produce a highly loaded, stable, and active enzyme aggregates. Therefore, the introduction of enzyme monomer and subsequent cross-linking them inside the nanocage will increase the confinement of enzyme aggregates. This method is also called ship-in-a-bottle effect and the confinement effect of MPS is usually increased by the bottle-neck pore structure. The major disadvantages of this approach are poor control in the aggregate sizes, and the substrates may not easily diffuse into the cross-linked enzymes. Hyeon's group immobilized $a$-chymotrypsin (CT) in MPS by cross-linking using glutaraldehyde (GA) [67]. The resulting cross-linked enzyme aggregates (CLEAs) showed an impressive stability with 10 times higher catalytic activity than that of adsorbed CT. Most recently, Reis et al. reported the immobilized lipase in MPS by cross-linking. They demonstrated that the entrapped enzymes were retained in the pores, and they could be reused five times [36].

\section{Single enzyme nanoparticles}

Kim et al. developed a novel method to synthesize single enzyme nanoparticles (SENs) [68,69]. The enzyme surface was modified with a nanometer thick porous organic/inorganic complex. This immobilization approach gives us a new technique to modify and stabilize enzyme molecules. The synthesis of SENs consists of three-step processes. First, the enzyme surface was modified with vinyl-group by reacting surface amino groups with acryloyl chloride to yield surface vinyl groups. Second, silane monomers such as methacryloxypropyltrimethoxysilane were added to the reaction mixtures for the polymerization of vinyl groups in hexane. After polymerization, the products were hydrolyzed and co-condensated for the further immobilization into MPS. Thus, each enzyme molecule is confined in a nanometer scale network to stabilize enzymatic activity without limitation in substrate diffusion.

\section{Stability enhancement}

Enzyme as a biocatalyst for industrial application is usually hampered by instability under extreme $\mathrm{pH}$, high temperatures, and organic solvent or denaturing agents. The following factors have been shown to affect the protein stability when enzymes are immobilized on MPS surface:

(a) Size-matching of MPS pores and enzymes: MPS with the pore size is smaller than the globular enzyme dimension; the enzyme will be adsorbed only on the outer surface which will suffer low stability. To increase the stability, it is required that the pore size be greater than the enzyme $[12,16]$. However, if the pore size of MPS is much greater than that of the enzyme, it tends to leach out during the reaction. The larger pore diameter also gives less surface curvature which may further affect the secondary conformation of the protein and reduce the enzymatic functionality (see below). It has been shown that the curvature of particle size will affect the conformation of protein [12,53,70-72]. Magner and coworkers functionalized six mesoporous materials with amine groups to immobilize chloroperoxidase (CPO). A periodic mesoporous organosilane (PMO) with pore size large enough to fit the enzyme inside the channels was 
found to have the best stability, and it could be reused 20 times with good retention of activity. However, the small pore size of PMO inhibited the entrance of enzyme molecules so the CPO rapidly lost activity under reuse [73]. Most recently, Takimoto et al. showed that size matching is important for fine-tuning activity even for the very large enzyme cellulase [74].

(b) Ionic strength of the solution: Eggers and Valentine reported that the $\alpha$-helical content of encapsulated apomyoglobin in sol-gel matrix was increased upon addition of salts [30],

(c) Immobilization method: Torrés and coworkers also reported the immobilized CPO on functionalized SBA- 16 . The results showed that both the activity and the stability strongly depended on the immobilization method. Moreover, the immobilized CPO by covalent binding showed an important improvement on catalytic activity and urea stability when compared to the physical adsorption [75].

\section{pH conditions}

The protonation of various amino acids in enzyme molecules is an important factor in the stability of enzyme structures. Recently, $\mathrm{Ma}$ and coworkers discussed the $\mathrm{pH}$ stability of immobilized papain in a large pore MCM-48 with the aid of glutaraldehyde. They reported that the immobilized enzyme on MPS surfaces exhibited a broader range of $\mathrm{pH}$ stability. This was attributed to a weak buffering effect of the surface silanol groups of MCM-48. In addition, the immobilized enzyme showed high stability after long operation time [60].

\section{High temperatures}

Increasing the thermal stability of the enzyme molecule has significant operational advantages, such as higher reaction and diffusion rates, high substrate solubility, high yield, and reduced risks from microbial contamination. It has been demonstrated that immobilized enzymes inside confined nanospaces of MPS can increase the stability against heat and organic solvent. Lee et al. studied the thermal stability of adsorbed cyt $c$ (molecular size $\sim 2.5 \mathrm{~nm}$ ) in different pore size of aluminum substituted MPS: MAS-9, MCM-48, MCM-41, and $Y$ zeolites $(0.74 \mathrm{~nm})[16,17]$. The results showed that MCM-41(48) offers adequate surface charge and optimum matching size so the embedded cyt $c$ can maintain its folding conformation and activity at boiling water temperature. On the other hand, cyt $c$ attached on outer surface of $Y$ zeolite lost its activity rapidly. However, the pore size of MAS-9 is so large that, when heated, confined cyt $c$ underwent denaturation (see Fig. 5a). Thermostability of the native hemoblogin $(\mathrm{Hb})$ and immobilized $\mathrm{Hb}$ on FSM has been studied by Urabe et al. The immobilized enzyme showed high absorption intensity of Soret band (73\% retention) than the native enzymes (only $34 \%$ retention) [49].

\section{Organic solvent}

Since many organic substrates are not water soluble, the employment of biocatalysts in organic solvents is becoming an important application. Enzyme catalyses in organic (a)

Pore size

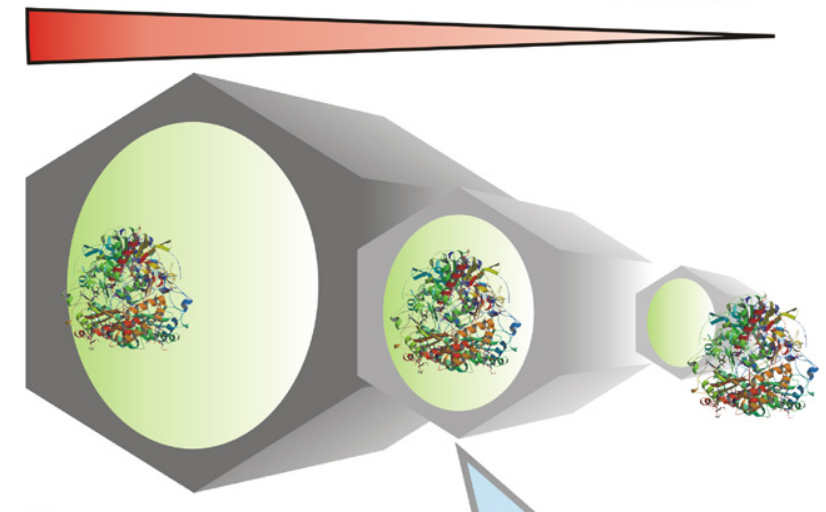

(b)

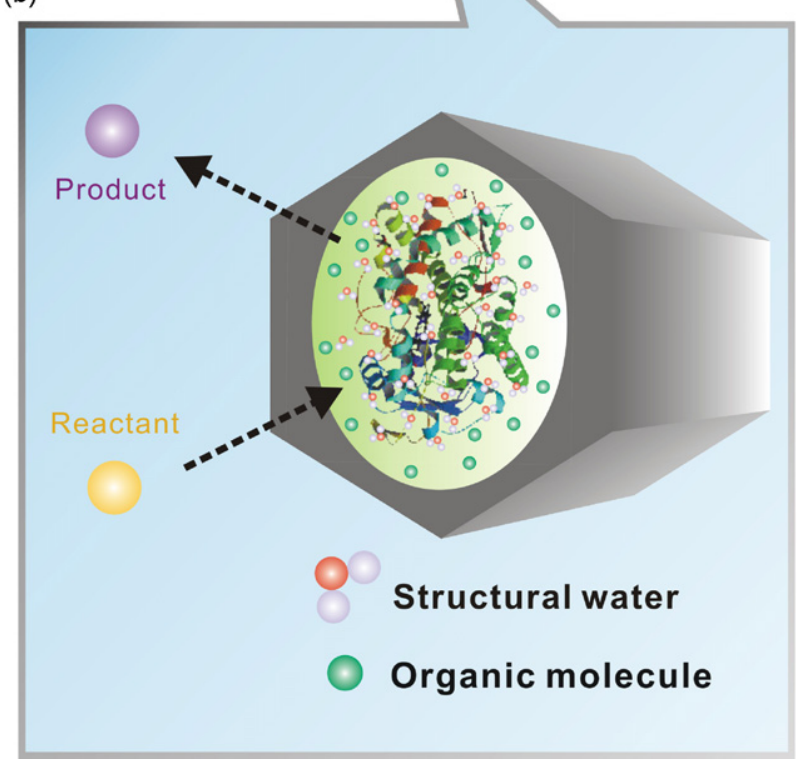

Figure 5 (a) Enzymes immobilized on MPS with different pore sizes: the pore size just matches the molecular diameter shows the best stability (middle), while the pore size larger (left) or smaller than the enzyme molecules shows lower stability (right). (b) Microenvironment effect on enzyme catalysis in organic solvent affects the enzyme-bound layer of water and determines the enzyme activity which is related to the water activity in MPS.

solvent come in three forms: (a) mixtures of water and water-miscible organic solvent (biphase system), (b) reverse micellar system, and (c) organic solvent systems. There are some reports about the increased stability in organic solvent of immobilized enzymes in MPS. Reis et al. showed that esterification with glycerol using immobilized lipase in different types of MPS catalysts was increased with decreasing water activity $\left(a_{w}\right)$ because lower water (hydrophobic) environment increased the stability of lipase [36]. Takahashi et al. reported that both the surface character and matching size are important to achieve high enzymatic activity in organic solvent [57]. They adsorbed HRP on several MPS (FSM-16, MCM-41, and SBA-15) with various pore diameters ranged from 2.7 to $9.2 \mathrm{~nm}$, and their activities in organic solvent were studied. The results showed that immobilized HRP on FSM-16 and MCM-41 had better matching size, thus it showed the highest enzymatic activity in 

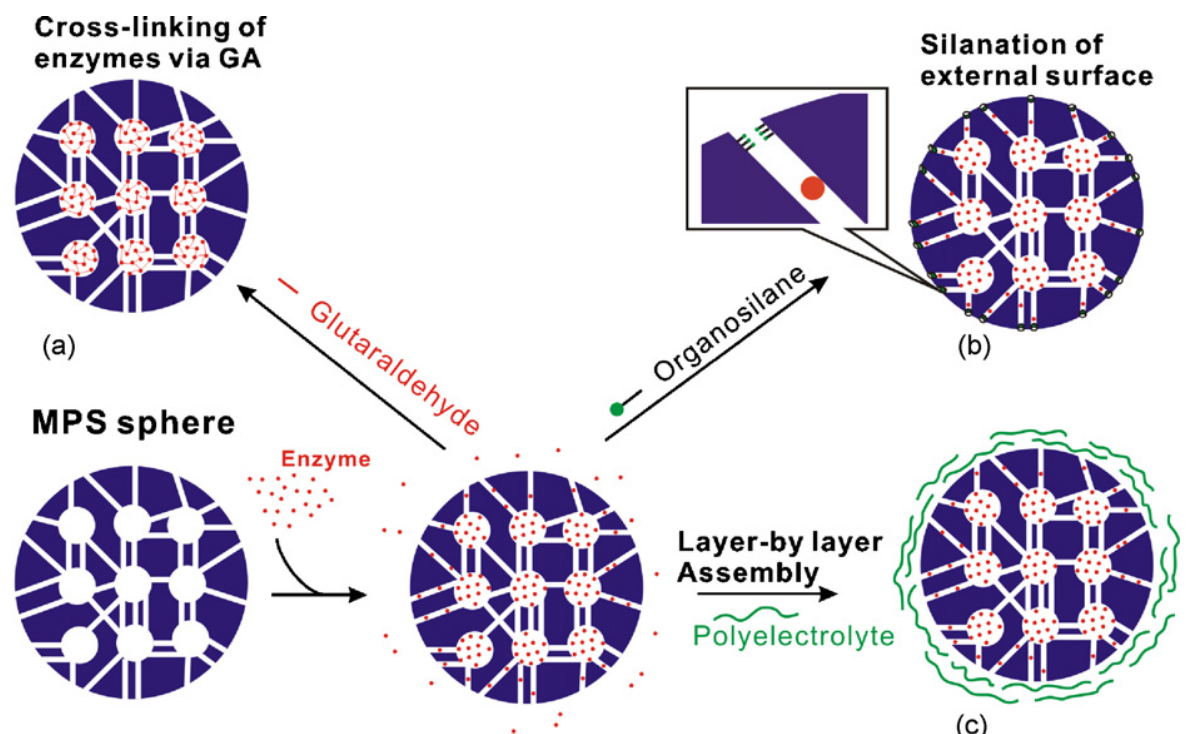

(c)

Figure 6 Three routes to avoid leakage of enzymes from MPS: (a) cross-linking of enzyme molecules inside the nanochannels of MPS via glutaraldehyde, (b) partial reduction of pore openings on the external surface by silanation of the pre-loaded enzymes, and (c) deposition of polyelectrolytes on the outside surface of MPS to cover the opening channels.

toluene. However, the immobilized enzymes in MPS with large or small pore size than the enzyme molecules showed lower enzymatic activity. Itoh et al. also modified MPS with ethanol for the immobilization of hemoglobin [76]. They showed that the encapsulated proteins into MPS resulted in increasing resistance to organic solvents, or surroundings, in comparison with the natural enzyme. Urabe et al. immobilized $\mathrm{Hb}$ in MPS and measured their peroxidase-like reactions under the chaotropic agent $\mathrm{Gdn}-\mathrm{HCl}$. Encapsulation of $\mathrm{Hb}$ retains better activity under high concentration of $\mathrm{NaCl}$ or $\mathrm{Gdn}-\mathrm{HCl}$ [49]. Ackerman and coworkers immobilized glucose isomerase (GI) into functionalized MPS. They also demonstrated that SBA-15 could provide a confined space to increase resistance at high concentration of urea [77]. Ye and coworkers immobilized $\alpha$-chymotrypsin and thermolysin inside microporous $Y$ zeolites and mesoporous dealuminized DAY zeolites to catalyze peptide synthesis in organic solvent. The immobilized enzymes showed high activity for the synthesis of peptide bond in organic media, and the catalysts can be reused five times [78].

\section{Enzyme re-use and enzyme leaching}

Immobilzed enzyme catalysts have the advantages of easy separation from the reaction mixture and re-usage. However, enzyme immobilization by adsorption and ionic attraction has the problem of leaching, especially when the enzymatic reaction must take place in a buffer solution with high ionic strength to optimize the enzyme activity. Three routes have been explored to avoid leakage of enzymes from MPS (see Fig. 6): (a) cross-linking of enzyme molecules inside the nanochannels of MPS with the aid of cross-linking agent glutaraldehyde [79], (b) partial closure of pore openings by silylation of the pre-loaded enzymes [19], and (c) deposition of layers of polyelectrolytes to cover the pore openings [20,80,81].

Ying and coworkers developed a pressure-driven method to immobilize enzymes (Candida antarctica lipase B) on hydrophobized mesoporous silica [82]. This approach showed a high enzyme loading and a reduced enzyme leaching. Zhao et al. studied the morphological effect on the immobilized lysozyme on MPS [83]. The loading amounts were increased with the decrease of particle size of MPS. Besides, increasing temperature favors a fast immobilization process of lysozyme into MPS.

Recently, several laboratories reported that the combination of magnetic nanoparticles in MPS has the advantage in enzyme separation and re-use $[61,84-88]$. These nanocomposites have many advantages, such as magnetically separable, high loading with enzymes, stable under harsh shaking conditions, resistant to proteolytic digestion, and recyclable for iterative use with little loss of enzyme activity [84].

\section{Modulating catalytic activities}

While it is often desirable to have both high stability and high catalytic activity for immobilized enzyme, these two goals are not necessarily optimized under the same condition. Sometimes, these requirements are even conflicting to each others. In the beginning, when scientists started using mesoporous materials to immobilize enzymes, their catalytic activies were mostly lower than those of free enzymes [89]. This is understandable due to the diffusion limitation in porous system. However, nanoscale biocatalyst system does offer many new possibilities in modulating catalytic activities [90]. Mesoporous materials can give many extra controls in confining effect, mobility and microenvironment. In this section, we review these modulating factors for controlling activities.

\section{Confining effect}

Natural enzymes can carry out various functions in a very crowded environment in cells. Thus, one would expect confined enzyme, if done properly, to give enhanced activity. 
Ackerman in a pioneering research showed that functionalized mesoporous silica promoted chain compaction for entrapped enzymes and give higher catalytic efficiency than free enzyme [52]. Future advances along this line will depend on our detailed understandings on confinement effect of proteins [91]. In fact, Lei et al. immobilized GI on functionalized MPS and they demonstrated that urea can promote the conformational change of enzyme molecules [77]. In the presence of urea, the immobilized GI in SBA15 showed the activity increase approximately double in comparison to that of native $\mathrm{Gl}$ in solution. Thus, immobilization of $\mathrm{GI}$ in SBA-15 increased not only the stability but also enzyme activity by changing enzyme conformation. The increase in catalytic activity by the addition of urea may be attributed to a loosening up of protein structure and an increase of conformational flexibility at its active site.

More recently, specific activities of confined enzymes are shown to be related to the orientation of the funnel connected to active site which may be controlled by specific attachment to the wall surface of nanopore. The access to the active site depends on the orientation of the enzyme molecule inside the nanochannel [18]. We have reported that the immobilized cyt $c$ (positively charged) on aluminum substituted MPS (negatively charged) produced a higher catalytic activity where a high-spin configuration of heme Fe-(III) was formed, very different from the native cyt $c$ (low-spin). The high-spin Fe(III) is formed when the axial ligands of Met-80 is replaced by $\mathrm{H}_{2} \mathrm{O}$ or a silanol group during the immobilization process. The high activity of immobilized cyt $c$ on this support may come from the fully opening of the heme groove and the active center becomes easily accessible to the substrate.

\section{Diffusion effect}

Immobilized enzymes on large pore of MPS usually have higher activity which is attributed to an increase of diffusion rates of reactants and products, i.e., higher diffusion in larger pore size of MPS. However, if the pore size of MPS is much larger than that of the target enzymes, then leaching of enzymes can occur and diminish the turnover number as we described earlier [16,17]. Lü et al. reported the immobilized Penicillin G acylase (PGA) on glycidoxypropyl modified MPS (cubic structure) and showed that covalent binding gave higher specific activity $\left(835 \mathrm{IU} \mathrm{g}^{-1}\right)$ and higher reusing times than physical adsorption $\left(624 \mathrm{IU} \mathrm{g}^{-1}\right)$ [58]. However, the higher loading density of glycidoxypropyl groups on MPS surface caused a decrease in the specific activity of immobilized PGA than that of low loading density. The effect may be attributed to the decreased mass transport of reactants and products inside the highly crowded nanochannels [58].

\section{Microenvironment}

When enzyme molecules are located inside the nanopores, the microenvironment would determine the accessibility of active sites and the configuration of the enzymes. This is especially true when the enzyme catalysis is taking place in organic solvent (see Fig. 5b). Hydrophobic/hydrophilic balance of wall-enzyme interaction will determine the enzyme configuration and thus its activity. Blanco et al. demon- strated that strong hydrophobic interaction can enhance the activity of lipase on MPS [51]. Furthermore, the hydrophobicity among substrate molecules and the active sites of the enzyme molecules can also affect catalytic activity. For example, subtilisin has a hydrophobic active site, thus it catalyzes the hydrophobic substrate with high activity in aqueous system. In contrast, a hydrophilic substrate has high diffusion rate into the active site when the reaction is taking place in a hydrophobic solvent [92]. Another example was given by Zhao et al. where they immobilized PGA into thio, phenyl, vinyl, aldehyde, and carboxylate modified SBA15. Here, hydrophobic interactions are the main forces for the immobilization of PGA in vinyl modified SBA-15 which showed a high initial enzymatic activity and a low $K_{m}$ value. The high activity of immobilized PGA was attributed to the hydrophobic modified MPS which can highly promote the entrance of substrate molecules [93].

Surface hydrophobicity can also be controlled by esterification of the surface silanol to form R-O-Si bond. Itoh et al. showed ethanol treated mesoporous silica can accommodate hemoglobin to give peroxidase-like activity [76]. Galarneau et al. further showed that the activity of lipase can be optimized by carefully tuning the hydrophilic/hydrophobic balance of the surface functional group in the nanopores [94].

Recently, another strategy for controlling the microenvironment of immobilized enzyme was reportedby using biosilica as support $[95,96]$. The good affinity between biosilica, made from silaffin-related polypeptide and silica sol, and enzyme results in very high payload. It can easily give $20 \% \mathrm{w} / \mathrm{w}$ loading (vs $\sim 1 \% \mathrm{w} / \mathrm{w}$ by other methods) and good stability of the native form which then results in high activity and stability [95].

\section{Multiple enzymes}

A multiple enzymes system can increase the catalytic efficiency by proximity effect where a short diffusion distance decreases the diffusion time to the nearest enzyme, i.e., the product from the catalysis of the first enzyme has a shorter diffusion distance to the second enzyme. This catalytic system is very efficient to speed up the reaction even with low substrate concentration. This effect is very similar to the enzymatic reactions within cell. In mitochondrion, the electrons from NADH and FADH can transfer to oxygen in several steps via the electron transport chain. Protein complexes (NADH dehydrogenase, cyt $c$ reductase, and cyt c oxidase) in the inner membrane of mitochondrion perform the transfer and the incremental release of energy is used to pump protons into the intermembrane space. This effect can be enhanced in the MPS system because the confined nanospace can limit the intermediate products to diffuse outside of the nanochannels. Torabi et al. reported the co-immobilization of cholesterol oxidase (COD) and horseradish peroxidase (HRP) on perlite surface [97]. The surface of perlite was first modified with 3-aminopropyltriethoxysilane and covalently bonded with COD and HRP via glutaraldehyde. The two immobilized enzymes showed better $\mathrm{pH}$ stability than native enzymes. In addition, the co-immobilized system had good reusable stability for the application in cholesterol determination or clearance. The immobilization of the enzymes 


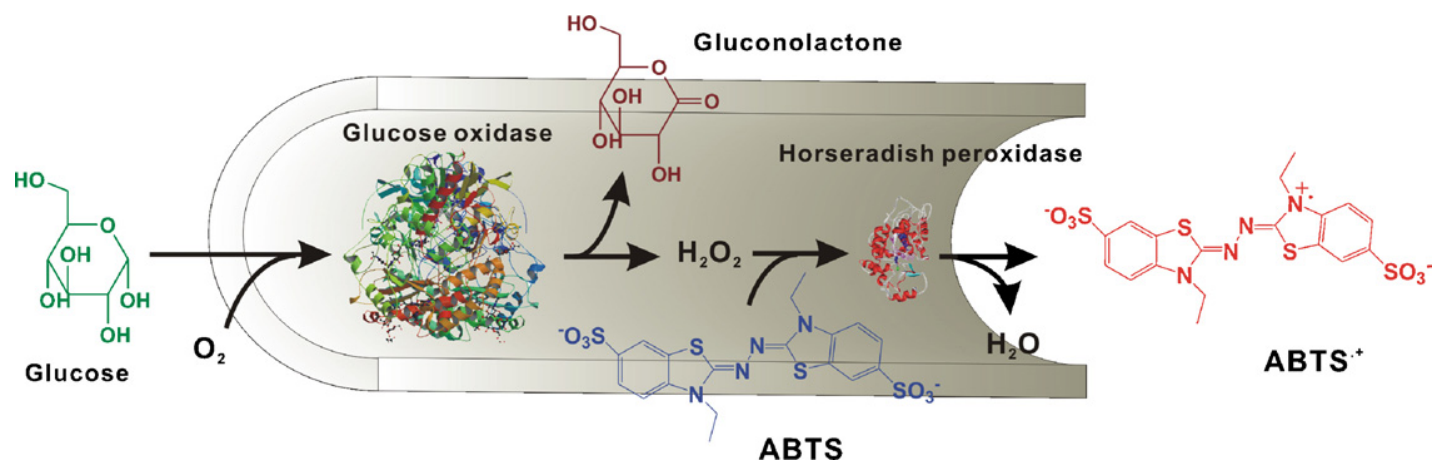

Figure 7 A bienzyme catalytic system based on co-entrapment of glucose oxidase and horseradish peroxidase in MPS nanochannels. Glucose oxidase catalyzes the oxidation of glucose to produce gluconolactone and hydrogen peroxide in the presence of oxygen and then horseradish peroxidase catalyzes the oxidation of $\mathrm{ABTS}$ to $\mathrm{ABTS}^{\circ+}$ which can be used to monitor the glucose content of diabetic samples.

CPO and GOx onto SBA-15 was investigated by Hartmann and coworkers [98]. Immobilized CPO catalyzes the oxidation of indole to 2-oxindole, while GOx is employed to generate the required oxidant hydrogen peroxide in situ from glucose. Dai et al. developed a novel bienzyme-channeling sensor by co-entrapment of GOx and HRP in the nanochannels of SBA15 [99] (see Fig. 7). This accelerated the electron transfer between the entrapped HRP and electrode. The entrapment of HRP molecules also avoided the aggregation of proteins on electrode, and the generation of hydrogen peroxide is immediately reduced by an electrocatalytic reaction with HRP. This device could have applications in monitoring the glucose content in diabetic samples.

\section{Artificial enzyme}

Since enzymes are easily denatured subject to environmental stresses. An alternative approach to circumvent these environmental sensitivity issues is to synthesize model compounds to mimic the active sites of enzymes,. This is particularly active in the field of metallo-enzymes. For instances, transition metals ( $\mathrm{Cu}, \mathrm{Fe}$, etc.) are used to carry out a specific reduction/oxidation (redox) reaction, and zinc are used structurally to maintain tertiary structure of the enzyme. But usually these model compounds in homogeneous solution are still somewhat sensitive to the environments and they show lower activity and selectivity than the corresponding enzymes. The protein backbone palys important roles in site-isolation and nanoconfinement to achieve a specific catalytic action. The idea here is to use the nanopores of MPS to immobilize the mimic compound and through designs in surface functionalization to mimic the protein skeleton. For example, di-copper complexes were immobilized on MPS surface in mimicking catechol oxidase to improve the catalytic activity in catechol oxidation. $[27,28]$.

There has been a lot of recent interest in using MPS to immobilize organometallic molecule for creating single-site chiral catalyst $[99,100]$. The chiral single-site heterogeneous catalysts were attached to nanopores via either covalent or hydrogen bonding attachment of a ligand to pore walls. Li and coworkers studied asymmetric epoxidation of styrene catalyzed by chiral $\mathrm{Mn}$ (salen) catalyst immobilized in nanopores and obtained excellent control in local environment to optimize selectivity [100]. Thomas and Raja reported the asymmetric catalysis of immobilized $\mathrm{Pd}(\mathrm{II})$ or $\mathrm{Rh}(\mathrm{I})$ complexes in the nanopore of MCM-41 [101]. They showed that nanospace confinement can improve product chiral selectivity via single-site catalysis. This approach opened up the prospect of performing heterogeneous enantioselective conversions in a novel manner, under the spatial restrictions imposed by the nanocavities within which the reactions occur. In particular, asymmetric products can be produced by confining prochiral reactants (and transition states formed at the chiral active center) to enhance the enantioselectivity of the anchored chiral catalyst. These studies demonstrated that selective pathways of synthetic, pharmaceutical, and biological significance can be achieved by the space confinement approach.

In this section, due to limitation of space, we only focus on those compounds that are biomimicking enzyme actions. Through its immobilization in the nanopores of MPS, one would like to study its catalytic activity and selectivity. Previously, we have encapsulated hydroxo-bridged binuclear copper model compounds in MPS to mimic the activity of catecholases (COs) and hemocyanin (Type III copper proteins) $[27,28]$. The encapsulated $\mathrm{HPC}\left((\text { phen })_{2} \mathrm{Cu}-\mathrm{OH}-\mathrm{Cu}(\text { phen })_{2}\right)\left(\mathrm{ClO}_{4}\right)_{3}$ (phen $=1,10$ phenanthroline) complexes were applied to carry out the catalytic oxidation of 3,5-di-t-butylcatechol (DTBC) to 3,5 -di- $t$-butylquinone (DTBQ) in mimicking COs. We demonstrated that the nanochannels of Al-MCM-41 solids provided confined spaces and surface charge to encapsulate and stabilize HPC complexes in carrying out the catalytic reaction where the HPC undergoes reversible transformation between bridging and non-bridging states (see Fig. 8). Here we may envision the framework of MCM-41 to be equivalent to the backbone of the protein skeleton of enzymes in which the two $\mathrm{Cu}(\mathrm{II})$ nuclei of HPC are fixed in position with the proper distance and configuration for catalytic activities. Similar concept has also been developed by Louloudi et al. where they modified silica surface with two polydentate ligands to bind $\mathrm{Cu}$ (II) ions [102]. Silica-supported Cu(II) complexes were evaluated for the catalytic oxidation of DTBC to DTBQ by dioxygen. The results showed that a key factor for efficient DTBC oxidation was related to the $\mathrm{Cu} . . \mathrm{Cu}$ distance. When the $\mathrm{Cu}$... Cu distance is matching the two 


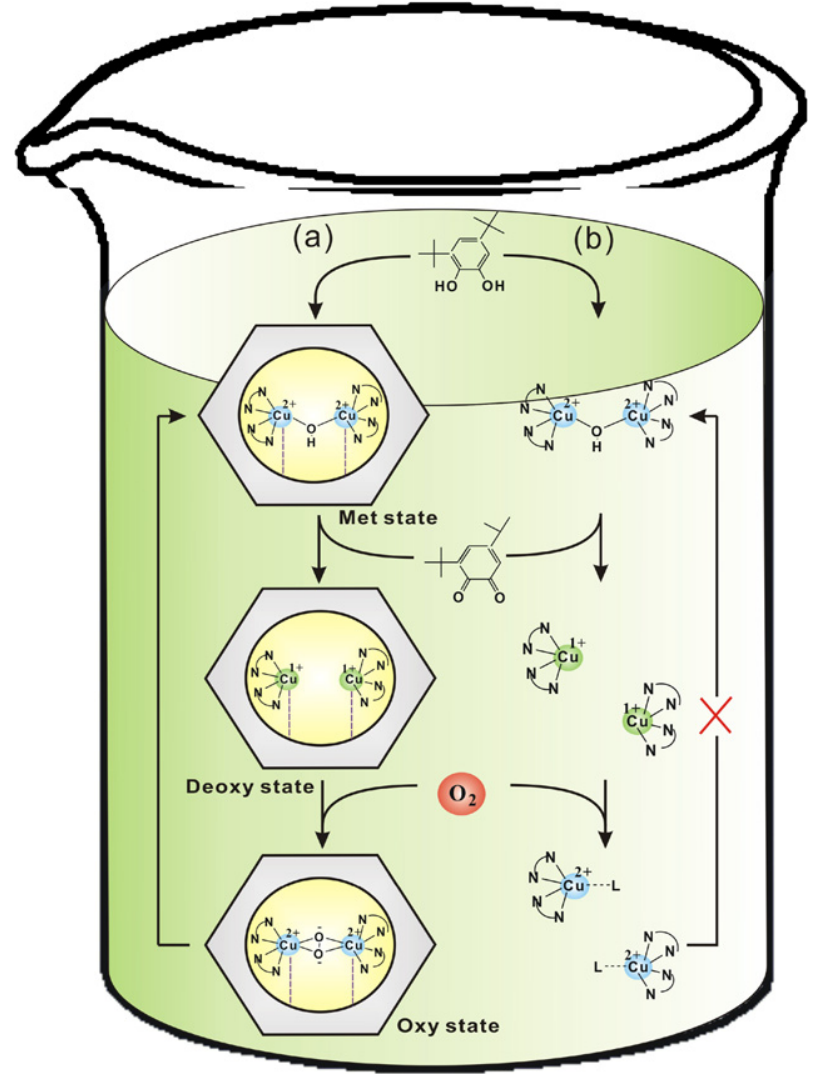

Figure 8 Dicupric complexes to mimic the activity of catecholases: (a) complexes encapsulated in the nanochannels of MPS which provide the confined spaces and surface charges to fix two $\mathrm{Cu}$ (II) ions with proper distance and configuration for reversible transformation between bridging and non-bridging states and (b) dicupric complexes in solution without encapsulation undergo irreversible dissociation under the non-bridging states.

oxygen distance of catechol molecule (2.7 $\AA$ ), it allows a bidentate coordination of DTBC molecule to the two copper ions.

Recently, Nantes et al. reported the encapsulation of microperoxidase-11 (MP-11) in MCM-41 where they studied the catalytic activity of phenol degradation in the presence of hydrogen peroxide as an oxidant [103]. Microperoxidases are hemepeptides produced by trypsin-catalyzed hydrolysis of cyt $c$ so one may attach various polypeptide chains onto the heme group to mimic the native enzyme. They reported the study of MP-11 consisting of (VQKCAQCHTVE) peptide fragment which was encapsulated in MCM-41 to mimic the enzymatic activity of hemoproteins. The resultant complexes have catalase and monooxygenase activity to catalyze the homolytic cleavage of the hydrogen peroxide and generate hydroxyl radicals. Nazari et al. also reported the encapsulation of $\mathrm{Fe}(\mathrm{III})$ protoporphyrin on MCM-41 pore surfaces to mimic the peroxidase enzyme. They studied the oxidation of phenol, guaiacol and synthesis of indophenol with this composite system. The results showed that the immobilized complexes were able to mimic horseradish peroxidase and had higher catalytic rate than the homogeneous system [104].
Since biomimetic compounds may have low stability and low solubility in aqueous solution, they may suffer inactivation in catalysis especially if there are changes in $\mathrm{pH}$ values, temperatures, or high concentrations of hydrogen peroxide, or in the presence of reactive solvents. Unprotected form of biomimetic compounds may undergo irreversible dissociation and decrease the reaction activity. The immobilization of biomimetic compounds in the nanospaces of MPS is a good strategy to increase stability, water solubility and re-usage of catalysts. We expect immobilized artificial and natural enzymes should be viable biocatalysts for industrial applications.

\section{Future perspectives}

Encapsulation of enzymes or biomimetic catalytic molecules in specially designed nanostructure of MPS may open the possibilities to improve the stability, catalytic activity and selectivity for the application of biocatalyst in the field of chemical synthesis, biosensor, and biomedicine [105]. In understanding the behavior of encapsulated enzyme or biomimetic moelcules, there are many interesting fundamental chemistry to be investigated.

Although immobilization can easily be achieved by fixing enzymes in the solid supports via a series of physical and chemical interactions, the different immobilizing processes of natural enzymes would often greatly influence the enzymatic activity and selectivity. Since the internal surface of MPS can be easily modified, one has the capability to modulate the chemical microenvironment of the confined enzyme through the functional groups used for immobilizing enzymes, including the length of the linker molecules, the nature of the linker and the non-linking surface functionality (hydrophilic or hydrophobic). Through surface modification of MPS, one can not only control the affinity of reaction substrate to enter the nanochannels but also modulate the 3D distribution of structural water on the surface of confined enzyme. Thus, the MPS/enzyme system, with increased thermostability, substrate solubility and mass transfer, may catalyze under non-natural conditions such as organic solvent or high temperature. In addition, the versatile pore structure of MPS materials has the potential for optimizing the orientation of the active site so one may hope to control the regioselectivity, enantioselectivity, or even to reverse the native selectivity [18]. This enhancement in the selectivity may come from the spatial confinement effect induced by the pore walls or the modification of a substrate directing ligand on the surface of MPS. For multiple enzyme system, MPS can be further designed to modify with various functional groups so the different enzyme molecules can conjugate at their specific sites to fit the optimum orientation. Besides, multiple enzymes have the advantages to develop those enzymes that require cofactor in the catalysis process [98]. Once the cofactor is consumed by the first enzyme, the second enzyme can continue regeneration of cofactor molecules.

For biomimetic enzyme system, it is still a challenge to build high performing catalyst with high efficiency and selectivity. We particularly favor to develop specially designed metal complexes to mimic the metalloenzyme with MPS mimicking the role of skeleton of the protein. Often, the 
difficulty in maintaining enzyme-like high catalytic activity with first-row transition metals mimic compound is its stability and accessibility. In reaction stage, the complex needs to have an open coordination site for the substrate. On the other hand, the coordinative unsaturation often leads to an unstable structure. Biological systems resolve this dilemma by site-isolation of the active metals in a protein matrix, which allows the metal sites to maintain coordinative unsaturation. The use of MPS as the supports to mimic the skeleton of natural enzymes brings the opportunity for the possible applications of surface chemistry to improve the coordination environment to increase stability, activity, and selectivity.

With good understanding about enzyme/MPS immobilization, applications of enzyme-loaded MPS may grow rapidly. They may be further used as a drug delivery vehicle [106,107], biosensor [99] and nanobioreactor. Enzyme delivery for therapeutic applications may benefit from a load-release mechanism in enzyme/MPS nanoparticles [106]. Lin and coworkers reported the use of MSN to deliver cyt $c$ into the cell [107]. They found that the released enzymes were kept in high activity to catalyze substrates oxidation in the presence of hydrogen peroxide as an oxidant. In biosensor application, natural enzyme suffers from drawbacks of instability. The encapsulated enzymes in nanopores have been shown as promising routes to stabilize the enzyme and improve the detection capability [99]. MPS has been developed as a nanoreactor for proteolysis $[108,109]$. Qiao et al. used a trypsin loaded MPS nanoreactor for proteolysis with nanoconfinement and protein enrichment being the main reason for high activity [110].

Designing methodology for proper immobilization of enzyme is a complex mixture of sciences and arts. There are often conflicting requirements in the stability, activity and separation of enzymes. Diversity of the process conditions necessarily requires the design of specific immobilized enzymes that can match the corresponding requirements for the desired application. Mesoporous materials offer nanostructure for enzymes that can be finely tuned through controlling their pore structure, transport and microenviroment. The physical chemistry of confined enzyme in mesoporous materials is more amendable to careful design and characterization. It is hoped that the immobilization of enzyme or enzyme mimetics in mesoporous materials can not only help obtain catalysts of high activity and stability, but also offer an approach for systematic understanding about enzymes in crowded nanospace environment.

\section{Acknowledgments}

This work was supported by a grant from the NSC Taiwan and Ministry of Education through Academy Excellent program. We thank Mr. Shih-Hsun Cheng for his assistance with the art work.

\section{References}

[1] J.M. Woodley, Trends Biotechnol. 26 (2008) 321. [2] L. Que, W.B. Tolman, Nature 455 (2008) 333.
[3] J.S. Dordick, A. Freeman, Curr. Opin. Biotechnol. 17 (2006) 559.

[4] H.E. Schoemaker, D. Mink, M.G. Wubbolts, Science 299 (2003) 1694.

[5] Biomolecular Catalysis: Nanoscale Science and Technology: ACS Symposium Series, No. 986, 2008.

[6] T. Nagayasu, M. Miyanaga, T. Tanaka, T. Sakiyama, K. Nakanishi, Biotechnol. Bioeng. 43 (1994) 1108.

[7] Y.-F. Chang, D.-F. Tai, Tetrahedron: Asymmetry 12 (2001) 177.

[8] G.F. Bickerstaff, Immbilization of Enzymes and Cells, Humana Press, Totowa, NJ, 1997.

[9] J. Livage, T. Coradin, C. Roux, J. Phys.: Condens. Matter 13 (2001) R673.

[10] J.S. Beck, J.C. Vartuli, W.J. Roth, M.E. Leonowicz, C.T. Kresge, K.D. Schmitt, et al., J. Am. Chem. Soc. 114 (1992) 10834.

[11] C.T. Kresge, M.E. Leonowicz, W.J. Roth, J.C. Vartuli, J.S. Beck, Nature 359 (1992) 710.

[12] M. Hartmann, Chem. Mater. 17 (2005) 4577.

[13] H.H.Y. Yiu, P.A. Wright, J. Mater. Chem. 15 (2005) 3690.

[14] X.S. Zhao, X.Y. Bao, W. Guo, F.Y. Lee, Mater. Today 9 (2006) 32.

[15] A. Vinu, M. Miyahara, K. Ariga, J. Nanosci. Nanotechnol. 6 (2006) 1510.

[16] C.H. Lee, J. Lang, C.W. Yen, P.C. Shih, T.S. Lin, C.Y. Mou, J. Phys. Chem. B 109 (2005) 12277.

[17] C.H. Lee, C.Y. Mou, S.C. Ke, T.S. Lin, Mol. Phys. 104 (2006) 1635.

[18] C. Lei, T.A. Soares, Y. Shin, J. Liu, E.J. Ackerman, Nanotech 19 (2008) 125102.

[19] L. Washmon-Kriel, V.L. Jimenez, K.J. Balkus, J. Mol. Catal. B: Enzym. 10 (2000) 453.

[20] Y. Wang, F. Caruso, Chem. Mater. 17 (2005) 953.

[21] Y.J. Han, J.T. Watson, G.D. Stucky, A. Butler, J. Mol. Catal. B: Enzym. 17 (2002) 1.

[22] J.F. Diaz, K.J. Balkus, J. Mol. Catal. B: Enzym. 2 (1996) 115.

[23] J. Deere, E. Magner, J.G. W., B.K. Hodnett, J. Phys. Chem. B 106 (2002) 7340.

[24] M. Shakeri, M. Shoda, J. Mol. Catal. B 54 (2008) 42.

[25] M. Vallet-Regi, F. Balas, D. Arcos, Angew. Chem., Int. Ed. 46 (2007) 7548.

[26] I.I. Slowing, J.L. Vivero-Escoto, C.W. Wu, V.S. Lin, Adv. Drug. Del. Rev. 80 (2008) 1278.

[27] C.H. Lee, S.T. Wong, T.S. Lin, C.Y. Mou, J. Phys. Chem. B 109 (2005) 775.

[28] S.T. Wong, C.H. Lee, T.S. Lin, C.Y. Mou, J. Catal. 228 (2004) 1.

[29] S. Jana, B. Dutta, R. Bera, S. Koner, Langmuir 23 (2007) 2492.

[30] D.K. Eggers, J.S. Valentine, Protein Sci. 10 (2001) 250; D.K. Eggers, J.S. Valentine, J. Mol. Sci. 10 (2001) 911.

[31] H.X. Zhou, K.A. Dill, Biochemistry 40 (2001) 11289.

[32] G. Ping, J.M. Yuan, M. Vallieres, H. Dong, Z. Sun, Y. Wei, et al., J. Chem. Phys. 118 (2003) 8042.

[33] E.J. Sorin, V.S. Pande, J. Am. Chem. Soc. 128 (2006) 6316.

[34] G. Schirò, M. Sclafani, F. Natali, A. Cupane, Euro. Biophys. J. 37 (2008) 543.

[35] R. Ravindra, S. Zhao, H. Gies, R. Winter, J. Am. Chem. Soc. 126 (2004) 12224.

[36] P. Reis, T. Witula, K. Holmberg, Micropor. Mesopor. Mater. 110 (2008) 355.

[37] A.P. Wight, M.E. Davis, Chem. Rev. 102 (2002) 3589.

[38] B. Tian, X. Liu, C. Yu, F. Gao, Q. Luo, S. Xie, et al., Chem. Commun. (2002) 1186.

[39] H.H.P. Yiu, P.A. Wright, N.P. Botting, J. Mol. Catal. B: Enzym 15 (2001) 81.

[40] A. Salis, D. Meloni, S. Ligas, M.F. Casula, M. Monduzzi, V. Solinas, et al., Langmuir 21 (2005) 5511. 
[41] R.J.P. Corriu, Y. Guari, A. Mehdi, C. Reyé, C. Thieuleux, L. Datas, Chem. Commun. (2001) 763.

[42] S.L. Burkett, S.D. Sims, S. Mann, Chem. Commun. (1996) 1367.

[43] M.H. Lim, C.F. Blanford, A. Stein, Chem. Mater. 10 (1998) 467.

[44] S. Huh, J.W. Wiench, J.-C. Yoo, M. Pruski, V.S.-Y. Lin, Chem. Mater. 15 (2003) 4247.

[45] Z. Tao, M.P. Morrow, T. Asefa, K.K. Sharma, C. Duncan, A. Anan, et al., Nano Lett. 8 (2008) 1517.

[46] J.H. Clark, D.J. Macquarrie, Chem. Commun. (1998) 853.

[47] V. Antochshuk, M. Jaroniec, Chem. Mater. 12 (2000) 2496.

[48] Y.H. Liu, H.P. Lin, C.Y. Mou, Langmuir 20 (2004) 3231.

[49] Y. Urabe, T. Shiomi, T. Itoh, A. Kawai, T. Tsunoda, F. Mizukami, et al., ChemBioChem 8 (2007) 668.

[50] J.M. Kisler, A. Dähler, G.W. Stevens, A.J. O'Connor, Micropor. Mesopor. Mater. 44, 45 (2001) 769.

[51] R.M. Blanco, P. Terreros, M. Fernández-Pérez, C. Otero, G. Díaz-González, J. Mol. Catal. B: Enzym. 30 (2004) 83.

[52] C. Lei, Y. Shin, J.K. Magnuson, G. Fryxell, L.L. Lasure, D.C. Elliot, et al., Nanotech 17 (2006) 5531.

[53] S. Hudson, E. Magner, J. Cooney, B.K. Hodnett, J. Phys. Chem. B 109 (2005) 19496.

[54] Y. Han, G.D. Stucky, A. Butler, J. Am. Chem. Soc. 121 (1999) 9897.

[55] E. Serra, A. Mayoral, Y. Sakamoto, R.M. Blanco, I. Diaz, Micropor. Mesopor. Mater. 114 (2008) 201.

[56] A. Vinu, V. Murugesan, O. Tangermann, M. Hartmann, Chem. Mater. 16 (2004) 3056.

[57] H. Takahashi, B. Li, T. Sasaki, C. Miyazaki, T. Kajino, S. Inagaki, Micropor. Mesopor. Mater. 44 (2001) 755;

H. Takahashi, B. Li, T. Sasaki, C. Miyazaki, T. Kajino, S. Inagaki, Chem. Mater. 12 (2000) 3301.

[58] Y. Lü, G. Lu, Y. Wang, Y. Guo, Y. Guo, Z. Zhang, et al., Adv. Funct. Mater. 17 (2007) 2160.

[59] G.T. Hermanson, Bioconjugate Techniques, Academic Press, San Diego, 1996.

[60] B. Zhao, B. Shi, R. Ma, Eng. Life Sci. 5 (2005) 436.

[61] Y. Zhu, S. Kaskel, J. Shi, T. Wage, K.-H. van Pée, Chem. Mater. 19 (2007) 6408.

[62] Y.X. Bai, Y.F. Li, y. Yang, L.X. Yi, J. Biotechnol. 125 (2006) 574.

[63] A. Schlossbauer, D. Schaffert, J. Kecht, E. Wagner, T. Bein, J. Am. Chem. Soc. 130 (2008) 12558.

[64] M. Miyazaki, H. Maeda, Trends Biotechnol. 24 (2006) 463.

[65] C. Xu, K. Xu, H. Gu, X. Zhong, Z. Guo, R. Zheng, et al., J. Am. Chem. Soc. 126 (2004) 3392.

[66] A.R. Herdt, B.S. Kim, T.A. Taton, Bioconjug. Chem. 18 (2007) 183.

[67] J. Lee, J. Kim, J. Kim, H. Jia, M.I. Kim, J.H. Kwak, et al., Small 1 (2005) 744.

[68] J. Kim, J.W. Grate, Nano Lett. 3 (2003) 1219.

[69] J. Kim, H. Jia, C.-W. Lee, S.-W. Chung, J.H. Kwak, Y. Shin, et al., Enzym. Microb. Technol. 39 (2006) 474.

[70] P. Roach, D. Farrar, C.C. Perry, J. Am. Chem. Soc. 128 (2006) 3939.

[71] M. Lundqvist, I. Sethson, B.-H. Jonsson, Langmuir 20 (2004) 10639.

[72] A.A. Vertegel, R.W. Siegel, J.S. Dordick, Langmuir 20 (2004) 6800.

[73] S. Hudson, J. Cooney, B.K. Hodnett, E. Magner, Chem. Mater. 19 (2007) 2049.

[74] A. Takimoto, T. Shiomi, K. Ino, T. Tsunoda, A. Kawai, F. Mizukami, et al., Micropor. Mesopor. Mater. 116 (2008) 601-606.

[75] J. Aburto, M. Ayala, I. Bustos-Jaimes, C. Montiel, E. Terrés, J.M. Domínguez, et al., Micropor. Mesopor. Mater. 83 (2005) 193.
[76] T. Itoh, R. Ishii, T. Ebina, T. Hanaoka, T. Ikeda, Y. Urabe, et al., Biotechnol. Bioeng. 97 (2007) 200.

[77] C. Lei, Y. Shin, J. Liu, E.J. Ackerman, Nano Lett. 7 (2007) 1050.

[78] G.W. Xing, X.W. Li, G.L. Tian, Y.H. Ye, Tetrahedron 56 (2000) 3517.

[79] P. López-Serrano, L. Cao, F. van Rantwijk, R.A. Sheldon, Biotechnol. Lett. 24 (2002) 1379.

[80] Y. Wang, F. Caruso, Chem. Commun. (2004) 1528.

[81] A. Yu, Y. Wang, E. Barlow, F. Caruso, Adv. Mater. 17 (2005) 1737.

[82] Y. Han, S.S. Lee, J.Y. Ying, Chem. Mater. 18 (2006) 643.

[83] J. Zhao, F. Gao, Y. Fu, W. Jin, P. Yang, D. Zhao, Chem. Commun. (2002) 752

[84] J. Kim, J. Lee, H.B. Na, B.C. Kim, J.K. Youn, J.H. Kwak, et al., Small 1 (2005) 1203.

[85] A.B. Fuertes, T. Valdes-Solis, M. Sevilla, P. Tartaj, J. Phys. Chem. C 112 (2008) 3648.

[86] J. Lee, D. Lee, E. Oh, J. Kim, Y.P. Kim, S. Jin, et al., Angew. Chem. Int. Ed. 44 (2005) 7427.

[87] Y.M. Zhang, J. Li, D.F. Han, H.D. Zhang, P. Liu, C. Li, Biochem. Biophys. Res. Commun. 365 (2008) 609.

[88] H.-A. Lin, C.-H. Liu, W.-C. Huang, S.-C. Liou, M.-W. Chu, C.-H. Chen, et al., Chem. Mater. 20 (2008) 6617.

[89] P. Wang, S. Dai, S.D. Waeszda, A.Y. Tsao, B.H. Davison, Biotechnol. Bioeng. 74 (2001) 249.

[90] P. Wang, Curr. Opin. Biotechnol. 17 (2006) 574.

[91] A.K. Dunker, A. Fernandez, Trends Biotechnol. 25 (2007) 189.

[92] C.R. Wescott, A.M. Klibanov, J. Am. Chem. Soc. 115 (1993) 1629.

[93] A.S.M. Chong, X.S. Zhao, Catal. Today 93-95 (2004) 293.

[94] A. Galarneau, M. Mureseanu, S. Atger, G. Renard, F. Fajula, New J. Chem. 30 (2006) 562.

[95] H.R. Luckarift, J.C. Spain, R.R. Naik, M.O. Stone, Nat. Biotechnol. 22 (2004) 211.

[96] Y. Zhang, H. Wu, J. Li, L. Li, Y. Jiang, Y. Jiang, et al., Chem. Mater. 20 (2008) 1041.

[97] S.F. Torabi, K. Khajeh, S. Ghasempura, N. Ghaemia, S.O.R. Siadat, J. Biotechnol. 131 (2007) 111.

[98] D. Jung, C. Streb, M. Hartmann, Micropor. Mesopor Mater. 113 (2008) 523.

[99] Z. Dai, J. Bao, X. Yang, H. Ju, Biosens. Bioelect. 23 (2008) 1070.

[100] C. Li, H.D. Zhang, D.M. Jiang, Q.H. Yang, Chem. Commun. (2007) 547.

[101] J.M. Thomas, R. Raja, Acc. Chem. Res. 41 (2008) 708.

[102] D. Zois, C. Vartzouma, Y. Deligiannakis, N. Hadjiliadis, L. Casella, E. Monzani, et al., J. Mol. Catal. A: Chem. 261 (2007) 306.

[103] J.C. Araujo, T. Prieto, F.M. Prado, F.J. Trindade, G.L.C. Nunes, J.G. dos Santos, et al., J. Nanosci. Nanotechnol. 7 (2007) 3643.

[104] K. Nazari, S. Shokrollahzadeh, A. Mahmoudi, F. Mesbahi, N.S. Matin, A.A. Moosavi-Movahedi, J. Mol. Catal. A: Chem. 239 (2005) 1.

[105] J. Kim, J.W. Grate, P. Wang, Trends Biotechnol. 26 (2008) 639.

[106] J. Ho, M.K. Danquah, H. Wang, G.M. Forde, J. Chem. Technol. Biotechnol. 83 (2008) 351.

[107] I.I. Slowing, B.G. Trewyn, V.S.-Y. Lin, J. Am. Chem. Soc. 129 (2007) 8845.

[108] W.Q. Shui, J. Fan, P.Y. Yang, C.L. Liu, J.J. Zhai, J. Lei, et al., Anal. Chem. 78 (2006) 4811.

[109] J. Fan, W.Q. Shui, P.Y. Yang, X.Y. Wang, Y.M. Xu, H.H. Wang, et al., Chem. Eur. J. 11 (2005) 5391.

[110] L. Qiao, Y. Liu, S.P. Hudson, P.Y. Yang, E. Magner, B.H. Liu, Chem. Eur. J. 14 (2008) 151. 
[111] A. Monnier, F. Schuth, Q. Huo, D. Kumar, D. Margolese, R.S. Maxwell, et al., Science 261 (1993) 1299.

[112] S. Inagaki, Y. Fukushima, K. Kuroda, J. Chem. Soc. -Chem. Commun. (1993) 680.

[113] Q.S. Huo, D.I. Margolese, U. Ciesla, P.Y. Feng, T.E. Gier, P. Sieger, et al., Nature 368 (1994) 317.

[114] D. Zhao, J. Feng, Q. Huo, N. Melosh, G.H. Fredrickson, B.F. Chmelka, et al., Science 279 (1998) 548.

[115] D. Zhao, Q. Huo, J. Feng, B.F. Chmelka, G.D. Stucky, J. Am. Chem. Soc 120 (1998) 6024.

[116] P. Schmidt-Winkel, W.W.J. Lukens, D. Zhao, P. Yang, B.F. Chmelka, G.D. Stucky, J. Am. Chem. Soc. 121 (1999) 254.

[117] P.T. Tanev, T.J. Pinnavaia, Science 267 (1995) 865.

[118] C.Y. Chen, H.X. Li, M.E. Davis, Micro-Mesoporous Mater 2 (1993) 17.

[119] Y. Han, J.Y. Ying, Angew. Chem., Int. Ed. 44 (2005) 288.

[120] F. Hoffmann, M. Cornellius, J. Morell, M. Froba, Angew. Chem., Int. Ed. 45 (2006) 3216.

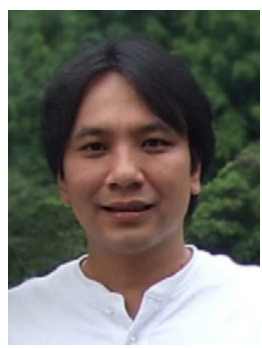

Chia-Hung Lee was born in Taiwan in 1975. He received his BS degree in Chemistry from Fu-Jen University, and Ph.D. from National Taiwan University in 2005. He is currently a postdoctoral fellow at the National Health Research Institutes. His research interests are the biocatlytic reactions in the confined nanospaces of mesoporous silica materials, and mesoporous silica nanoparticles for biomedical applications.

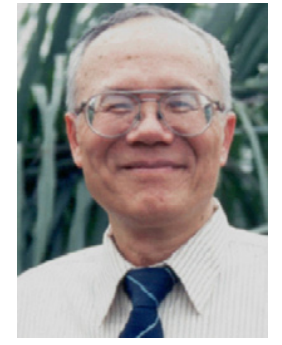

Tien-Sung Lin was born in Taiwan. He received his BS from Tunghai University, MS from Syracuse University, and PhD from the University of Pennsylvania in 1969. After postdoctoral fellowship at Harvard University, he joined faculty at Washington University in St. Louis where he is now a Professor of Chemistry. He was a scientist-in-residence at National Argonne Laboratory (1980-1981). He was a visiting professor of the following institutions: Leiden University, Institute of Physical and Chemical Research (RIKEN), University of Freiburg, and National Taiwan University. His research interests are molecular spectroscopy, dynamics and reactivity of organic solids, organometallic complexes and mesoporous materials.

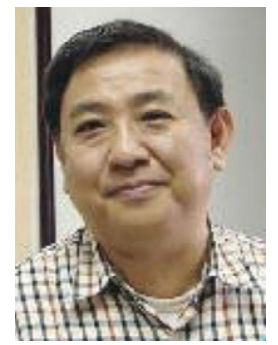

Chung-Yuan Mou earned his Ph.D. in theoretical chemistry from Washington University in Saint Louis, in 1975. After postdoctoral research, he joined National Taiwan University in 1978 where he is now University Chair Professor of Chemistry.. In 1983-1984, he was visiting fellow at L'universite Libre de Bruxelles. He has been awarded National Chair Professor (2000), Chinese Chemical Society Medal (2002), Cozarrelli Prize (2007) of PNAS for best paper. His research interests are biomedical applications of mesoporous silica, heterogeneous catalysis, supercooled water, confined enzymes, and biomineralization. 